\title{
Nutritional factors and cardiovascular disease risk in Black African and Black Caribbean women: a cross-sectional study
}

\author{
C. Evwierhoma ${ }^{1}$, A.P. Moore ${ }^{2}$, L.M. Goff ${ }^{2}$, A. Aghili ${ }^{1}$, S. Comegna $^{3}$, G. Begum ${ }^{3}$ and \\ A.R.A. Adegboye ${ }^{4}$ \\ ${ }^{1}$ London Metropolitan University, 166-120 Holloway Road, London N7 8DB, \\ ${ }^{2}$ King's College London, Stamford Street, London SE1 9NH, \\ ${ }^{3}$ University of Westminster, 115 New Cavendish Street, London W1W 6UW and \\ ${ }^{4}$ University of Greenwich, Avery Hill Campus, Eltham, SE9 $2 U G$.
}

People of Black African (BA) and Caribbean (BC) heritage form the third largest ethnic group in England and Wales ${ }^{(1) .}$ Evidence shows they experience higher rates of overweight/obesity, stroke and type 2 diabetes compared to the general population but lower risk of heart disease, which may be explained by the favourable lipid profile they exhibit ${ }^{(2,3)}$. There are limited UK studies on their dietary habits and health. The aim of the current study was to assess nutritional intake and cardiovascular disease (CVD) risk factors in UK BA and $\mathrm{BC}$ women.

A convenience sample of self-ascribed BA and BC women, aged 19-64 years, were recruited $(n=44)$ from the ATTITUdinal DEterminants of diet and lifestyle (ATTITUDE) study. Cholesterol was measured using a portable CardioChek Blood Analyser, blood pressure using a digital blood pressure monitor and dietary intake via triple pass $24 \mathrm{hr}$ recall. Ethical approval was obtained from London Metropolitan University, King's College London and Westminster University. Percentage energy, total fat, saturated fat, carbohydrate, and fibre and salt intake were calculated and under-reporting was assessed using the Goldberg equation ${ }^{(5)}$. A sensitivity analysis conducted on nutrient intakes with under-reporters removed.

Nutritional intake and CVD risk factors are shown in Table 1. Sixty three percent of participants were overweight or obese. Analysis of the dietary data revealed higher intakes salt, free sugars, fat and saturated fat than recommendations and lower intake of carbohydrate ${ }^{(4)}$. Sensitivity analysis was conducted to investigate the impact of under-reporting $(n=22)$. Reported data remained unchanged except for fibre intake, which was lower in the under-reporters (14.9g compared to 21.0g) $(\mathrm{P}=0.004)$. Blood lipid profiles and blood pressure data were within recommendations.

Table 1. CVD risk factors and nutritional intake data $(n=44)$

\begin{tabular}{|c|c|c|c|}
\hline & Mean or median ( \%) & SD or $\left[\operatorname{IQR}\left(25^{\text {th }}, 75^{\text {th }}\right)\right]$ & $\%$ of participants not within recommended limits \\
\hline Age & 34.2 & 11.3 & \\
\hline Weight $(\mathrm{kg})$ & 78.6 & 20.4 & \\
\hline BMI $\left(\mathrm{kg} / \mathrm{m}^{2}\right)$ & 26.5 & {$[23.7,32.6]$} & Overweight $27 \%$, Obese $25 \%$, Morbidly obese $11 \%$ \\
\hline Waist Circum. (cm) & 89.9 & 16.0 & $68 \%$ above recommendation of $<80 \mathrm{~cm}$ \\
\hline Waist:Hip Ratio & 0.8 & 0.1 & \\
\hline Total Cholesterol (mmol/L) & 4.1 & 0.9 & \\
\hline HDL-cholesterol (mmol/L) & 1.5 & 0.4 & \\
\hline TotalCholesterol/HDL-cholesterol & 2.8 & 0.7 & \\
\hline Blood pressure (systol.) & 114.6 & 9.3 & \\
\hline Blood pressure (diastol.) & 72.6 & 9.3 & \\
\hline \multicolumn{4}{|l|}{ Dietary Intake } \\
\hline $\mathrm{CHO}(\%$ total energy) & $45 \%$ & 8 & $75 \%$ below recommendation of $50 \%$ \\
\hline Free sugar ( $\%$ total energy) & $8 \%$ & 5 & $64 \%$ above recommendation of $5 \%$ \\
\hline Fibre $(\mathrm{g})$ & 17.0 & 7.4 & $93 \%$ below recommendation of $30 \mathrm{~g}$ \\
\hline Saturated Fat ( $\%$ total energy) & $12 \%$ & 5 & $55 \%$ above recommendation of $11 \%$ \\
\hline Fat ( $\%$ total energy) & $36 \%$ & 6 & $45 \%$ above recommendation of $35 \%$ \\
\hline Salt $(g)$ & 5.4 & 3.2 & $30 \%$ above recommendation of $6 \mathrm{~g}$ \\
\hline
\end{tabular}

In conclusion, the anthropometric and certain dietary measures would indicate increased risk for developing CVD in BA and BC women, however, blood lipid profile and blood pressure measures were within healthy ranges.

1. Office for National Statistics. (2012). Ethnicity and National Identity in England and Wales 2011.

2. Lip G, Barnett A, Bradbury A et al. (2007) J Hum Hypertens, 21:183-211.

3. Goff LM, Griffin BA, Lovegrove JA et al. (2013) Diab Vasc Dis Res, 10(4):315-323.

4. British Nutrition Foundation (2017) Nutrition Requirements. www.nutrition.org,uk

5. Goldberg GR, Black AE, Jebb SA et al. (1991) Eur J Clin Nutr, 45:569-581. 